\title{
A BIM APPROACH FOR THE ANALYSIS OF AN ARCHAEOLOGICAL MONUMENT
}

\author{
Angela Bosco ${ }^{1}$, Andrea D’Andrea ${ }^{1}$, Massimiliano Nuzzolo², Patrizia Zanfagna \\ ${ }^{1}$ Centro Interdipartimentale di Servizi di Archeologia, Università di Napoli “L’Orientale”, Italy \\ ${ }^{2}$ Charles University Prague, Czech Republic
}

\section{Commission II}

KEY WORDS: 3D reconstruction, Egypt, Solar Temple, BIM

\begin{abstract}
:
In 2010 an Italian team started new on-field investigations in the area of the Sun Temple of Niuserra, $6 \mathrm{~km}$ south of the pyramids of Giza. The archaeological research was planned to re-examine the monument after its discovery in 1898 . The work was mainly aimed at a general evaluation of the archaeological structures, still visible, in order to establish an updated plan of the temple. More than 100 scans and several 3D models by close-range photogrammetry have been acquired, processed and integrated to virtually reconstruct the archaeological area.

To manage all available 3D datasets, allowing to propose new hypothesis about the monument, a BIM has been developed. Thanks to this approach different categories of environmental and technological objects have been created and analysed. The paper deals with the recent achievements, especially regarding the hierarchical conceptualisation of the architectural components. In particular, the contribution dwells on the analysis of the monument starting from the identification of a parametric library built on the semantic decomposition of the 3D replica.
\end{abstract}

\section{INTRODUCTION}

In January 2010 an Italian archaeological mission started new investigations in the area of the Temple of Niuserra. This monument, built by the sixth ruler of the fifth dynasty (about $2.400 \mathrm{BC}$ ), is the first building completely dedicated to the cult of the sun in ancient Egypt. Moreover, out of the six sun temples known from the historical sources, the sanctuary of Niuserra is the only one which is still largely preserved and visible nowadays. The importance of analysing this temple is thus clear, particularly when considering that the complex was first discovered by Ludwig Borchardt in 1898 (Figure 1), but only recently investigated again (Nuzzolo and Pirelli 2011, D'Andrea et al. 2014).

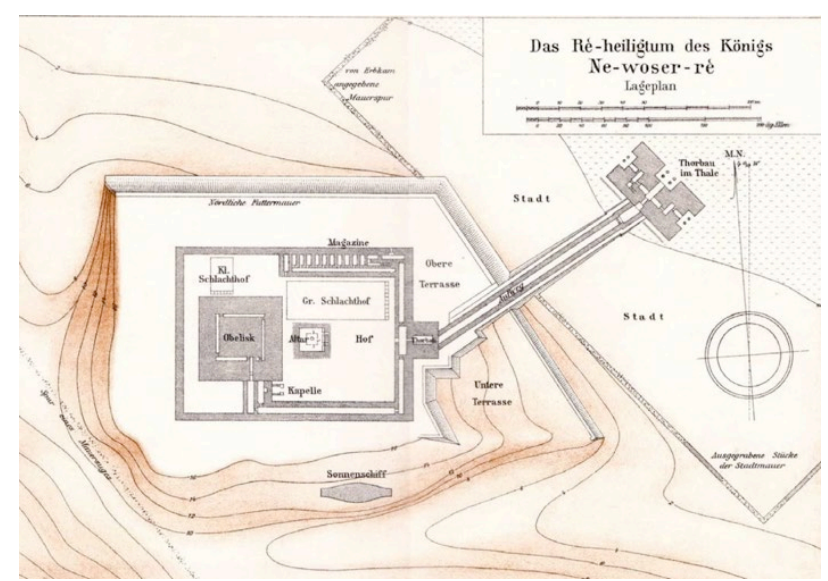

Figure 1: The Sun Temple of Niuserra. General map (Borchardt 1905).

Because of the severe state of disrepair of the whole building already in the time of its discovery, the reconstruction proposed by the Borchardt is mainly based on the shape of a determinative employed in the contemporary tomb of the fifth dynasty priest Ty at Saqqara, where the name of the temple is defined by a two-stepped building in the form of a squat obelisk on a large basement (Figure 2).

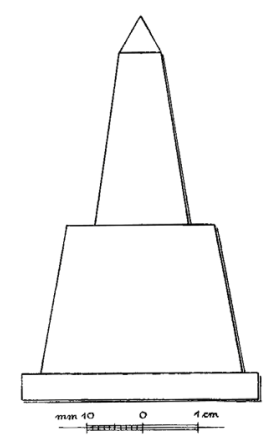

Figure 2: the determinative found in the contemporary tomb of the fifth dynasty priest Ty at Saqqara.

According to the German scholar, this part of the temple was shaped as a huge, wide obelisk $\left(20 \mathrm{~m}\right.$ wide and $36 \mathrm{~m}$ high, $81^{\circ}$ slope) on top of a pedestal basement in the form of a large, truncated pyramid ( $40 \mathrm{~m}$ wide and $20 \mathrm{~m}$ high, $76^{\circ}$ slope). An ascending corridor, probably went up twice all around the basement, finally reaching the base of the obelisk on the eastern side.

Borchardt funded his reconstruction on the ratio between the two parts represented in the hieroglyphic sign. As the basement was preserved for $20 \mathrm{~m}$, the German archaeologist estimated for the whole building a height of $56 \mathrm{~m}$.

In order to check the reconstruction provided by Borchardt, the new project has been primarily addressed to the creation of a $3 \mathrm{D}$ digital model of the temple by means of laser scanner (figure 3 ) integrated by close-range photogrammetry (figure 4) (D'Andrea et al. 2014).

During four campaigns (2010-2017) different surveys were carried out with the target to acquire the archaeological area of 
the temple of Niuserra. Moreover, many notes, photos and drawings were taken on field mainly for those blocks and architectural elements which were collapsed and had not been put in place by Borchardt when the temple was discovered.

On account of the increasing volume of acquired data, a BIM approach was started to facilitate data-sharing, the analysis of structural architectural elements still in situ, the extraction of plans, sections and perspective drawings and, finally, the reconstruction of the temple and its relationships with the surroundings monuments.

The BIM represents a complete information system of the monument which includes all digital data and written notes not easy manageable according to normal procedures. This information system allows to make available geometries, documents, photos, notes acting as a fundamental and exhaustive knowledge platform on the monument.

\subsection{The 3D data-acquisition and processing}

In the framework of the new on-field investigations, different data-acquisition campaigns were carried out with the aim to survey the monument.

In 2010 two 3D surveys (in January and December) affected the Chapel and the Room of Seasons, in the southern side of the temple, as well as the storehouse, in the north-eastern side, and the area of the obelisk and the altar in the central part of the temple. All 47 acquired scans, carried out by an Imager 5003 of Zoller\&Frölich, were processed and registered on the base of 122 GCPs measured by total station. Some photos were taken by a digital camera and then superimposed, by JRC 3D Reconstructor, on the final 3D model to have a more realistic rendering.

Different maps and sections, documenting the state of conservation of the monument, were extracted from the model; in particular, was generated a top view map, showing the perimeter of the obelisk, the internal corridor and the collapse of the core masonry walls on the south-western corner. Some plans, built thematically on the basis of the materials of the blocks used for the outer and inner core of the obelisk, were superimposed in a GIS on the map drawn by Borchardt, to compare the surveys and highlight possible discrepancies.

As the verification showed that the Borchardt map contained some inaccuracies, especially as regards the structure of the obelisk, in December 2014 a new 3D survey was undertaken with the aim to study more in depth the whole monument. In six days, 56 scans were acquired by Faro Focus 3D X130. Fourteen high-resolution scans, covering the entire site, were used as reference for the alignment of the other ones including those of the first two campaigns. All point-clouds were then merged and duplicated points removed; the final model was simplified to have a lighter $3 \mathrm{D}$ reconstruction without losing any information useful for the analysis of the monument (figure 3 ).

To reach a more realistic rendering of the archaeological area, the laser scanner campaign was integrated by some acquisitions by image-based modelling technique (figure 4 ). The integration of the geometric precision of measurements by laser scanner with the high-resolution texturized surfaces by image-based modelling allowed to analyse in detail the remains and to provide information about the materials and architectural elements of the sanctuary.

More than 2.000 photos were shouted for four areas and then processed by Agisoft Photoscan. To check the precision and accuracy of the models some points were extracted from the scans to reference the model to the grid taken by the laser scanner. All the 3D data were, finally, merged and analysed also with the aim to highlight the damages caused to the archaeological structures after the 2011 Egyptian revolution. In 2017 a new survey was carried out to complete the missing parts not acquired by close-range photogrammetry in the previous campaign. Furthermore, additionally, individual pieces not in-situ, but presenting specific features to be recorded in detail (e.g., all inscribed blocks, whenever possible), were taken to obtain usable and manageable 3D models; these digital replicas can be easily moved and rotated to re-create single components of the collapsed architectural structures and simulate possible reconstruction of parts not more visible.

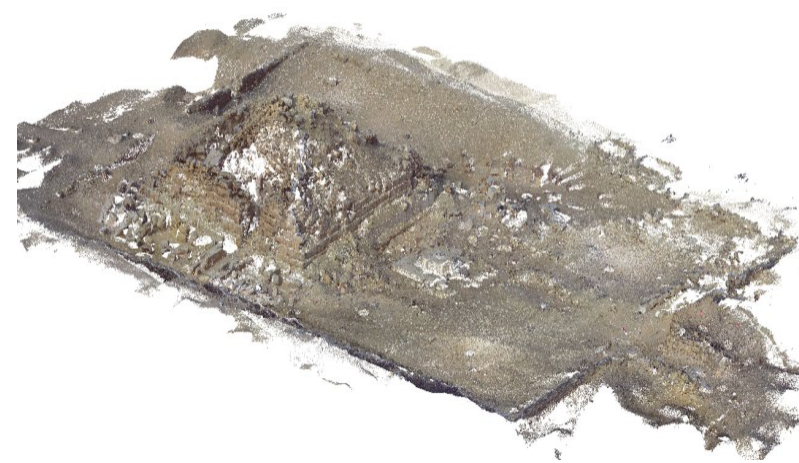

Figure 3: laser scanner survey: the final model of the temple acquired in 2014 .

Data acquisition has been carried out by DJI Osmo with a sensor Sony X3 mounted on a pole. The campaign has been integrated by a data-acquisition with two very high-resolution cameras (Nikon 5300D and Nikon D750). At the end of the onground work, more than 2.000 images of the entire temple were shouted producing different texturized point-clouds and meshes; the model were referenced by using the virtual 3D grid built in 2014 .

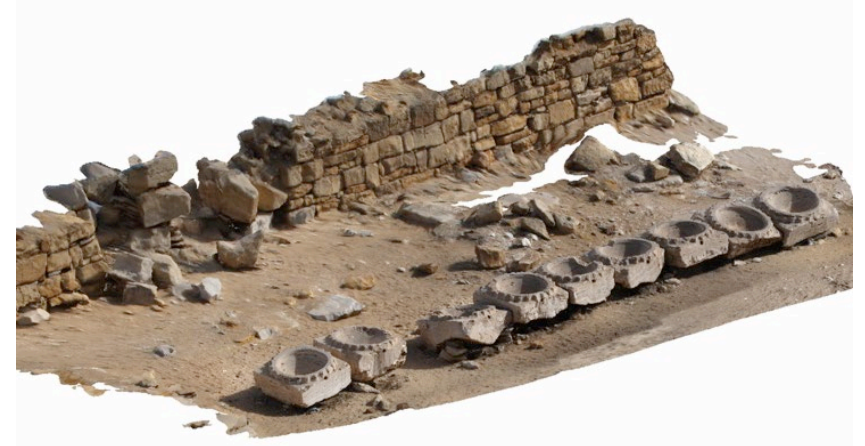

Figure 4: Close-range photogrammetry survey: the area of basins

All 3D datasets acquired were integrated to have a complete and enriched model of the monument. In addition to the simple measurement or calculation of whatever architectural element, from the model is possible to extract ortho-photos, prospects, sections and plans, which are fundamental for an accurate drawing and for a correct interpretation of the temple.

On the basis of the digital surveys, the notes taken on field about the not in-situ blocks, the similarities and proportions with contemporaneous buildings mainly as regards the masonry and the constructive techniques (Arnold 1991), a virtual reconstruction of the temple started with the aim to hypothesize the original shape and volumes of the monument. To better manage all information acquired so far, not only the geometry, the colours and the materials of the monument, but also all the notes describing each single component of the structure, a BIM 
approach was chosen.

The methodology followed in the implementation of the BIM application will be discussed in the third section. In the next section a short introduction about BIM and modelling archaeological heritage will be presented in order to highlight the potentiality of this new approach to guarantee the reliability and transparency of the reconstruction process and rigour in the computer-based visualization according to Sevilla Principles and London Charter.

\section{RELATED WORKS}

The term HBIM (Historic Building Information Modelling) has been coined in 2007 (Murphy et al. 2007) as a BIM whose parametric rules could be deduced from " $18^{\text {th }}$ century architectural patterns books". Differently by the usual BIM approach, formerly implemented for modern civil engineering to integrate the needs of the designers with those of the building companies and industries, the HBIM represents an effective method in producing documentation about historical buildings, materials and architectural elements. The main feature of the HBIM is designing object libraries and new shapes on historic data. Murphy, McGovern, Pavia (2007) highlighted the potentiality of the HBIM in the field of the built and architectural heritage not only to produce conventional engineering surveys (orthographic plans, elevations, and sections), but also in terms of objects identification and semantic classification of existing historic structures (Arayici 2008).

From 2007 to today different HBIM has been designed and implemented with good results demonstrating the effectiveness and adaptability of this approach. The combination of the digital survey with a parametric reconstruction of the existing historical structures provides a complete information system useful for different purposes ranging from documentation to interpretation, management, valorisation, restoration and safeguard (Lopez et al. 2018). BIM for heritage represents a big challenge and opportunity to make available, in a virtual environment, all the data related to a single monument.

While in built heritage the architectural elements are frequently well preserved and therefore the creation of categories of objects is quite simple, in the archaeological contexts the structures are very often badly preserved, partially visible or strongly restored or modified respect to their original shape. Furthermore, differently from the HBIM, no historic data are available on the constructive techniques and architectural patterns, excepting "De architectura" of Vitruvius for the roman architecture until I sec B.C. Often, archaeological reports on the excavations and related documentation are the only available "historic" data.

Contrarily from the traditional HBIM case-studies, in archaeological contexts it is much more difficult create standard libraries of items, architectural elements and masonries. Frequently, the buildings are visible at foundation level, the surface is quite often irregular, and the only still visible shapes of a structure are uncertain. Furthermore. the main architectural elements of a monument can be only virtually reconstructed.

Probably for these reasons few models have been so far tested in the archaeological field (Achille, Lombardini and Tommasi 2015, Garagnani and Govi 2017, Historic England 2017, Scianna et al., 2015; Trizio, Savini and Giannangeli, 2018). In large part these applications deal with virtual reconstructions; in only one case (Historic England 2017) a BIM has been implemented for a preventive archaeological project.

Most above-mentioned studies highlight that virtual reconstruction is a hard issue, as no adequate algorithms have been developed to extract from scans, through automatic or semi-automatic modelling procedures, the objects needed for the rebuilding of an ancient monument.

From an archaeological point of view, BIM works a sort of 3D GIS, but more powerful and flexible and with tools and functionalities to enrich the models and make more transparent the $3 \mathrm{D}$ reconstructive steps.

As the BIM is a container including and sharing all data related to an archaeological monument, this approach allows to compare the re-building process to the textual analysis where the sources are philologically discussed, examined and, finally, approved by the scientific community. In this perspective the application of BIM in the archaeological research will represent a bigger challenge than in the historical field. BIM will help the archaeologists to use widely the digital methods to analyse and rebuild virtually and scientifically the past.

\subsection{Research aims}

The formalization or discretisation process of the archaeological remains is carried out through different steps whose goals is to decompose semantically the monument thanks to a reverse engineering approach (Points/Scans-to-BIM) helping to capture the structure information underlying the archaeological structure. The digital survey and the consequent detailed technical analysis of the geometries, materials, architectural components and masonry are parts of a complete knowledge process allowing to understand and hypothesize the original shape of the monument.

While in the virtual reconstruction each of these choices is encapsulated in the conclusive model, in the BIM the final output is the result of a more complex approach not limited to the simple reconstruction of the lines and volumes; BIM makes available a complete knowledge of all technical aspects of the monument. Furthermore, each step in the implementation of the final model is supported by the documentation organized according of the semantic classification of every single element or parametric object (block, architrave, column, base, doorstep, etc.).

These considerations and remarks were at the base of choice to use a BIM for the virtual reconstruction of the Sun Temple of Niuserra. In particular, the challenge addressed to the understanding of the structure, the different buildings, each part of it, the interrelationships between the architectural components and, finally, to the analysis of the correctness and precision of the reconstruction provided by Borchardt at the beginning of the last century.

After showing in subsection 1 the data collection process, the next section will deal with the design and development of the library of the parametric objects, the semantic classification of the architectural components and the level of reliability/tolerance adopted in the creation of the single element.

In absence of written source, the semantic decomposition of the monument has been carried out through the analysis of the 3D model and on the basis of similarity and parallelism with contemporaneous monuments or structures.

\section{DEVELOPED METHODOLOGY}

As BIM deals with environment and technological systems, the first step was the analysis of the model to facilitate the composition and decomposition of all architectural elements according to different level of detail. From the 3D replica many 
information about the building and the masonry were extracted; all the blocks and slabs were singularly examined to identify those elements showing the design of the building and the different structures.

This preliminary work allowed formalizing the whole complex according to UNI 8290-1981 classification set-up for building systems. It consists of:

\section{PART $\cap$ COMPONENT $\cap$ SUB-SYSTEM $\cap$ ELEMENTARY SYSTEM $\cap$ SYSTEM}

- SYSTEM corresponds to the whole Solar Temple;

- ELEMENTARY SYSTEM consists of classes of technological units and the main systems for the working of the temple: structure system, closing, internal and external partitioning, etc.;

- SUB-SYSTEM are the technological units of each elementary system, as the foundation and horizontal and vertical partitioning, etc.;

- COMPONENT are the classes of the basic technical elements as architrave, jambs, internal and external walls, etc.;

- PART includes each element identifiable as a component like blocs, slabs, etc.

Even if the UNI 8290-1981 classification has been developed to identify requirements for modern civil buildings, it fits well to the features of Egyptian architecture which shows the following main elements: simplicity; modularity and standardization; and portability (Arnold 1991).

While in the previous step of the work, addressed to create a 3D replica, the model was mainly used to extract $2 \mathrm{D}$ sections and maps for the documentation of the shape of the monument and its state of conservation, thanks to BIM it has been possible to setup a wider workflow allowing the creation of spatial and geometrical 3D objects enriched by a formalized description

The first step of a BIM approach has been the import of the scans. To clean and merge all scans in only one-point cloud, manageable by BIM, all 3D data were imported into Recap. The processed point-cloud was, finally, imported into Revit. Unfortunately, Revit isn't able to change or modify the original the point-cloud, nor it is possible to transform the point-cloud into mesh. For this reason, the 3D base to be drawn into Revit has to be processed into the software for the 3D (Scene, Reconstructor, Recap) before importing 3D data into Revit.

The absence of tools in Revit for the editing of the 3D pointcloud it makes difficult to carry out a more powerful and accurate scan-to-BIM procedure. Other BIM software seems to have the same strong limitations in the management of the 3D survey. Furthermore, as the archaeological features are frequently irregular or only partially preserved, it is impossible to use automatic algorithm able to transform millions of points into archaeological standardised objects.

For these reasons the plans and sections remain fundamental elements to define the macro conceptual masses and the smaller architectural elements of the temple.

The analysis of the point-cloud allowed identifying a first volume with the construction of a plane-volumetric element supporting the decomposition, or rather, the understanding of how the monument was built.

As Revit uses a different language to describe the technological system, one of the first tasks was the mapping of the categories of schema, based on the UNI standard, onto the conceptual groups of Revit. This is the final result:

\begin{tabular}{|l|l|}
\hline \multicolumn{1}{|c|}{ UNI } & \multicolumn{1}{c|}{ Revit } \\
\hline System & Family \\
\hline Sub-System & Type \\
\hline Component & Instance \\
\hline
\end{tabular}

Then, a hierarchy of the various architectural elements has been extracted according to the following schema:

Category $=$ group of abstract elements used to create the model or a documentation design of a building (walls, architraves, doors, etc.) and annotation text;

Family $=$ classes of abstract elements forming a category. Families assemble elements with common parameters (property), function, and graphical representation;

Type $=$ each family presents different abstract types. For example a type can be constituted by objects belonging to one family with specific dimensions;

Instance $=$ the instances are the real objects, the single elements positioned in a monument or in drawing.

After analysing the 3D model, a parametric library was created from the categories of architectural elements, corresponding to different components of the technological and constructive system (table 1, figure 5). These objects were identified and drawn through a manual intervention in absence of automatic or semi-automatic procedure. This step of the BIM represents a delicate phase in the implementation of BIM, as an adequate level of detail has to be chosen at the beginning of the process to guarantee the correctness of the future analysis.

\begin{tabular}{|c|c|}
\hline Technological unit & Technological elements \\
\hline $\begin{array}{l}\text { A. Vertical closure } \\
\text { Vertical elements with the } \\
\text { function to separate the interior } \\
\text { space from the outside }\end{array}$ & $\begin{array}{l}\text { - Perimeters walls } \\
\text { - Vertical external } \\
\text { features }\end{array}$ \\
\hline $\begin{array}{l}\text { B. Lower horizontal closure } \\
\text { Horizontal elements of building } \\
\text { with the function to separate the } \\
\text { interior from the underlying soil } \\
\text { or the foundation structures. }\end{array}$ & $\begin{array}{l}\text { - Slabs on the ground } \\
\text { - Horizontal feature }\end{array}$ \\
\hline $\begin{array}{l}\text { C. Horizontal closure of outdoor } \\
\text { spaces } \\
\text { Horizontal elements with the } \\
\text { function to separate the interior } \\
\text { space from the external one. }\end{array}$ & - Slabs of open space \\
\hline $\begin{array}{l}\text { D. Top closure } \\
\text { Horizontal elements with the } \\
\text { function to separate the interior } \\
\text { space from the underlying } \\
\text { external spaces. }\end{array}$ & $\begin{array}{l}\text { - Covers } \\
\text { - Horizontal external } \\
\text { features }\end{array}$ \\
\hline
\end{tabular}

Table 1: The Technological System for the closings elements. The figure 5 shows the images of each element. 
A

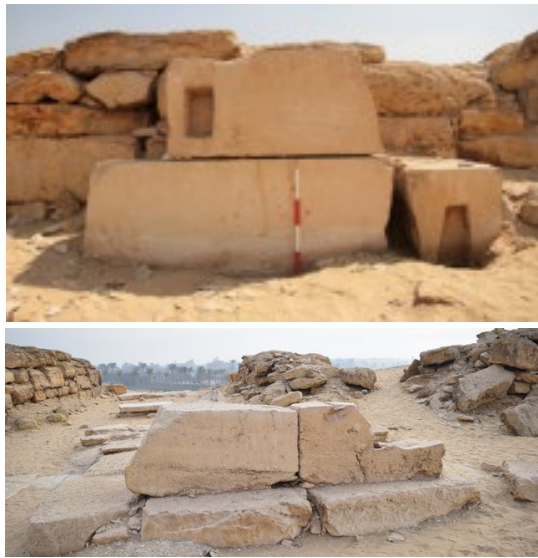

C

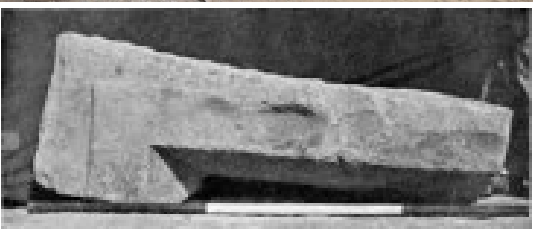

(From Borchardt 1905, figure 19)

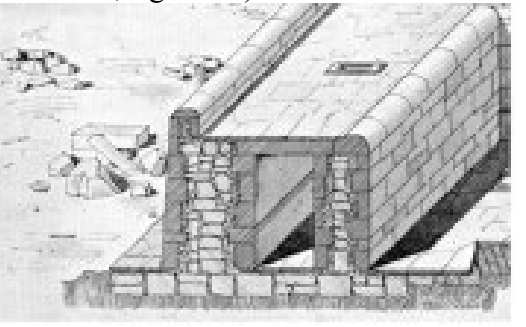

(From Borchardt 1905, figure 42)

Figure 5: Images of closure elements related to table 1.

This semantic approach contributed to the formal and physical representation of the $3 \mathrm{D}$ reconstruction of the monument; different 3D geometrical objects have been created and associated to a description including code, material, dimension and provenance.

For the construction of the parametric library all objects were analysed in $3 \mathrm{D}$ dimensions by starting from a general approach to reach a particular view. The families have been created by drawing them, individually in AutoCad or importing them as mesh blocks into Revit. In the latter case decimation has been required. Each element of the sub-system has been then analysed and correctly assigned to a specific category (figures 6 and 7).

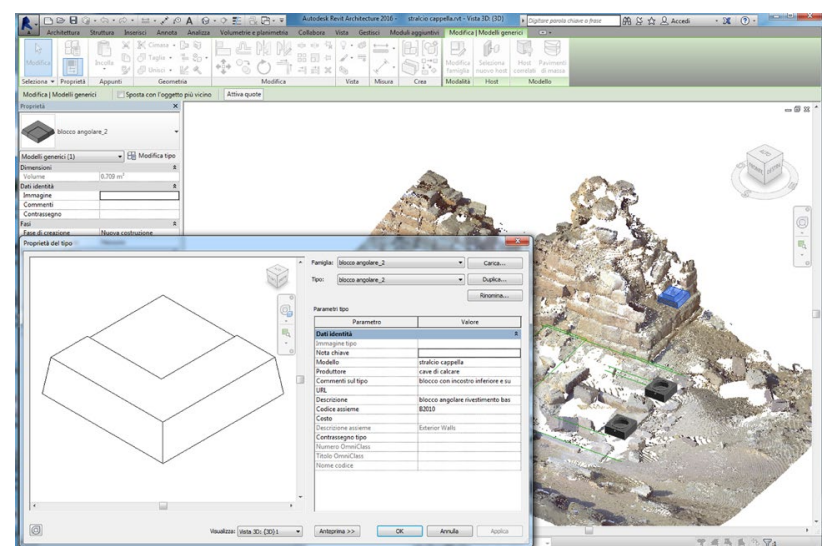

Figure 6: An example of family: an angular block and its description.

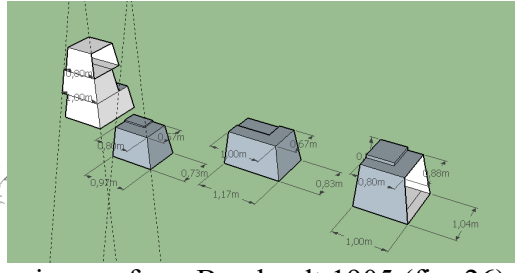

Figure 7: On the left an image, from Borchardt 1905 (fig. 26), showing the corner construction; on the right side, the single blocks (in grey) drawn from the 3D survey and their assemblage.

Revit allows creating the taxonomy of families, types and single instances in the architectural model. As Revit has been designed mainly for the industries, a fundamental step of the project implementation was the creation of the parametric library that included a detailed description of all archaeological artefacts. Thanks to this formalized data-organization, called Abaci in Revit, BIM allows to associate physical instances to other sources (drawings, photos, notes, etc.) manageable by a Database (figure 8 ). The DB can be easily queried, and the geometrical objects visualised.

In this way, BIM works as 3D GIS even if data are not formalized according to a semantic or conceptual model and all spatial relationships are based exclusively on topological correlations without any hierarchy (Tobias 2016); BIM, as GIS, provide an organization of the information that is the architecture at the base of the Information System.

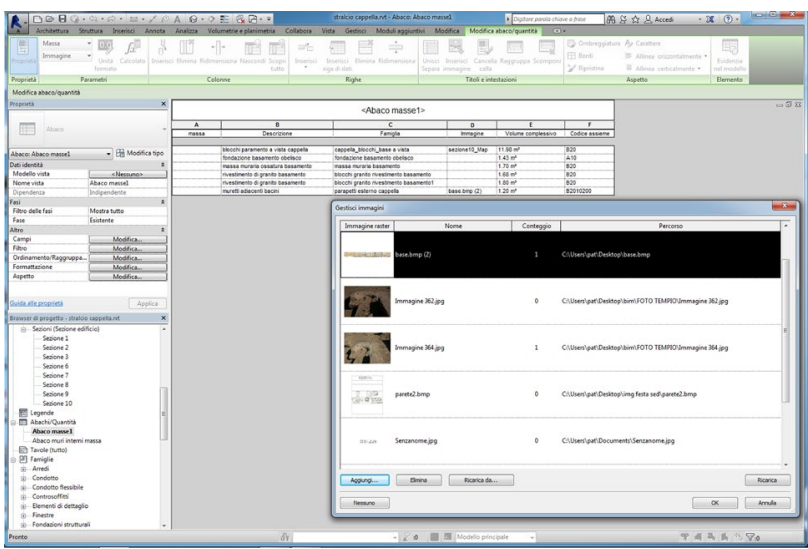

Figure 8: The parametric library and the Abaci.

The conceptual approach of Revit, particularly flexible in the starting phases, allows to examine all components and to create classes or entities of standard volumes, which can be integrated in the model. In this way, it is also easy to calculate the amount of building materials necessary for the construction of each part or sub-system of the temple and evaluate what it misses or what has been destroyed.

Finally, the analysis of the technological system allows hypothesizing some alternative proposals about the reconstruction of the obelisk and the truncated basement. In particular, the simulation of horizontal planes can help us in the understanding of the original architectural structure of some components of the temple. This is extremely important as the shape and height of the obelisk haven't yet been clarified and represents one of the main targets of investigations (Figure 9). 


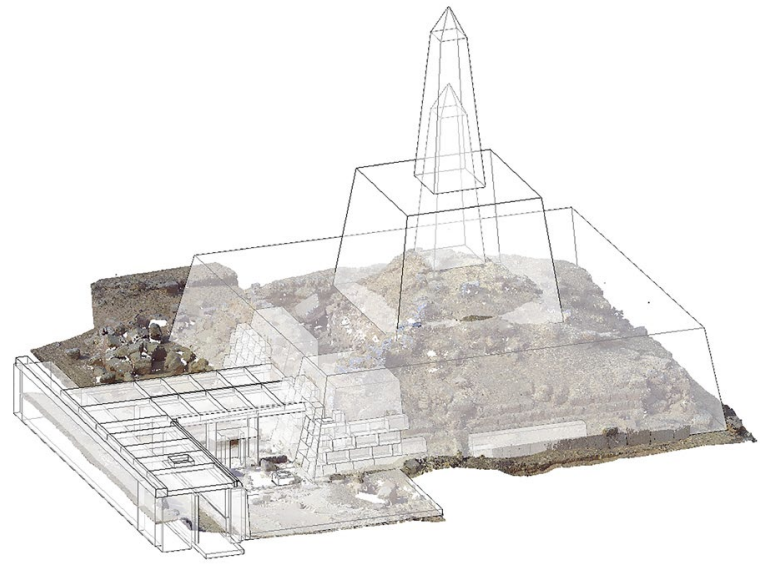

Figure 9: The comparison of the two-alternative hypothesis about the shape and height of the obelisk and truncated basement.

Furthermore, thanks to the geographical coordinates it is possible to collocate the monument in a simulated landscape. The model can be rotated to check the correct illumination of all its sides in order to improve the rendering of the building material according to the real positioning of the monument respect to the sun. It is also possible to deepen the spatial location of the monument and highlight some parts, which were probably used as astronomic points of observation (figure 10). Thanks to the correct orientation of the temple, its ramp and the valley temple, it is also possible to evaluate other atmospheric factors as rainfall and winds (direction, frequency, etc.). Moreover, in Revit the model can be passed into Google Earth; the overlapping on the modern landscape is particularly useful to better understand the artificial terraces system used for the foundation of the temple.

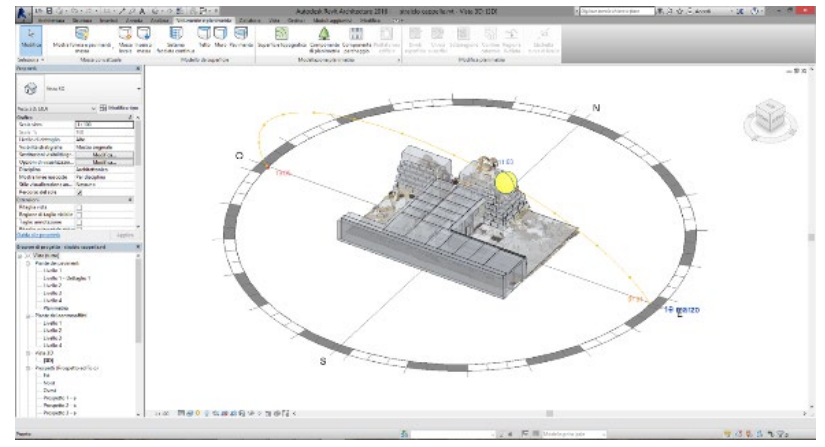

Figure 10: The positioning of the sun visualized thanks to the environmental system.

\subsection{The Application on Niuserra Temple}

In the modelling process each block has been draw and repeated schematically by keeping a high level of tolerance with the aim to assure the precision of volumes and the masses. If necessary, a user can examine in detail the state of art of the single elements with their irregularities and missing parts by analysing the point-cloud; Revit allows to show the point-cloud, representing the archaeological reality, through the semitransparent masses of the final 3D rendering.

The superimposition of the conceptual mass of the obelisk on the point-cloud highlights the co-planarity of the planes and volumes of the building. In some areas, phenomena and dynamics of collapse or movement of the structures can be better identified and understand allowing to reconstruct the monument and his state of abandon (figure 10).

On the site, during the on-field investigations, some collapsed blocks were identified and surveyed. Thanks to the general model these blocks were virtually assembled to compose the missing technological elements as part of the subsystems (Figure 11). The parallelism with other architectural contemporaneous examples in Egypt also supported the assembling process.

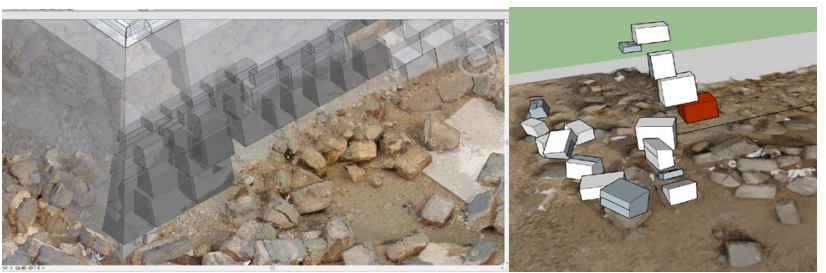

Figure 11: On the left side the re-positioning of the blocks collapsed in the S-W corner of the temple; on the right side the process of reverse-enginering.

At the end of the modelling step, the 3D virtual model gave the opportunities to deepen some questions about the reconstruction of some crucial parts of the monument. Not all issues have been so far examined and solved, but BIM showed as a fundamental tool for a clear and accurate 3D reconstruction.

Among the open questions some will be faced in the future with new excavation and exploration trying to clarify, for example, the foundation of the truncated basement or of the obelisk. Other doubts could be explained through a better analysis of the 3D model. Now, the research focuses on some issues raised by the inaccuracy of the Borchardt maps.

As it was fundamental to understand how the technical elements have been used for the building system, BIM supported the analyse of the construction process adopted by the ancient Egyptians. Some details will be better clarified.

For instance, from the model it is possible to calculate the inclination of the cladding blocks, covering the basement, and compare them with those of the access corridor inside the structure. The comparison allowed formulating a reliable reconstruction of this part of the monument. Furthermore, it is not clear the number of laps, under an internal corridor or tunnel hypothesized by Borchardt, running around the basement to reach the on top the starting-point of obelisk (Figure 12).

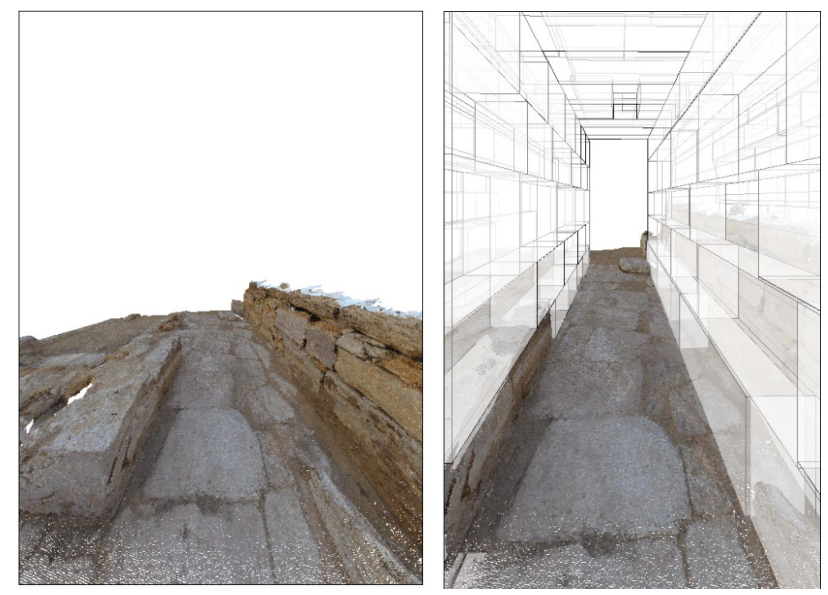

Figure 12: The inner corridor from laser scanner survey (on the left side) and its virtual reconstruction (on the right side).

Another example comes from for the floor of the large courtyard, historically defined as a slaughterhouse. From the few elements still in situ, which present regular grooves, it is 
possible to verify, thanks to a virtual plane, the relationship of the floor with the alabaster basins close to the south walls. By examining the $3 \mathrm{D}$ model, it is possible to clarify that single object (slabs of floor and basins) was surely in relation as the virtual plans shows a system of outflow of the liquid contained in the basins.

Modelling and application of the dynamic simulation of horizontal planes and virtual structures has clarified the real architectural structure. The recognition of precise construction standards of specific elements allowed relocating with certainty, architectural component necessary for structure of the building. All these questions will be tested into BIM and possibly validate. Thanks to a BIM more detailed results have been reached or new issues have been fixed. In some cases, BIM confirmed the suggestions providing by Borchardt (i.e. basins), while in other one it was possible to generate new hypotheses (i.e. corridor) to reject the reconstruction of the German archaeologist.

For the whole area investigated (horizontally and vertically) it is possible to analyse the co-planarity of the planes (overlapping the conceptual mass with the cloud of points) (figure 13) and highlight, in some points, possible mechanisms and collapse dynamics helping the study of the structural model.

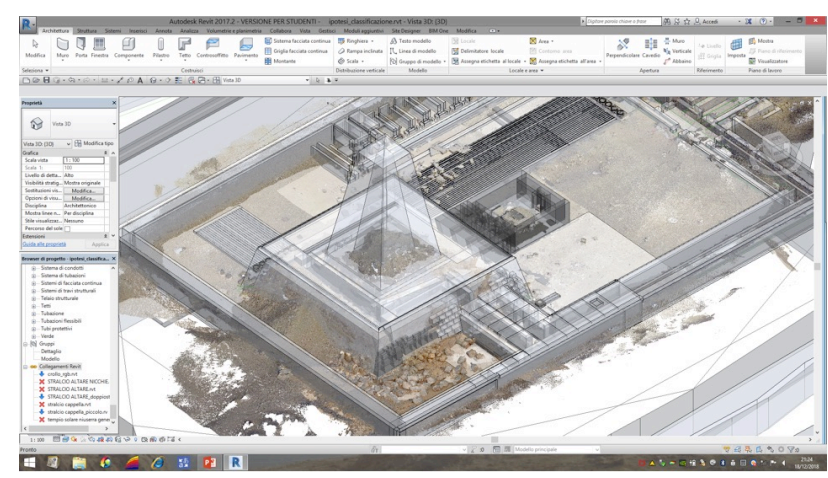

Figure 13: The 3D reconstruction superimposed on the laser scanner survey.

\subsection{Problems and future developments}

To operate in the correct way on complex archaeological structures, it is necessary to work at different levels of resolution or reliability. Data-collection and data-capture are two relevant phases for a good BIM project as they can guarantee precision in the geometry and realism in the images. Furthermore, two different methods of acquisition return information on a large scale and characterized by high details.

Currently the most important limitation of the BIM for existing archaeological structures is the capacity to manage highresolution $3 \mathrm{D}$ acquisitions and meshes which could constitute the perfect support on which to build the parametric object, volume and surfaces.

BIM is ready for its use in archaeology, but it needs more functionality to transform millions of $3 \mathrm{D}$ points into objects. Conversely by the historical buildings, in archaeology the pointcloud is the only referenced model that it is possible to use to extract the parametric elements. Currently a commercial plug-in allows importing the simple and light meshes that become useless to extract accurate geometries from surveys of archaeological structures. To overcome these issues, we are testing the Dynamo free plug-in to import meshes and automatically create parametric objects. First attempts have been based on not high-resolution meshes; as the results are satisfying, we planned to adopt this procedure to process the models provided by SfM (Figure 14).
These tests could give interesting solutions to the implementation of a semi-automatic parameterization method to the translation of archaeological heritage into architectural and structural components.

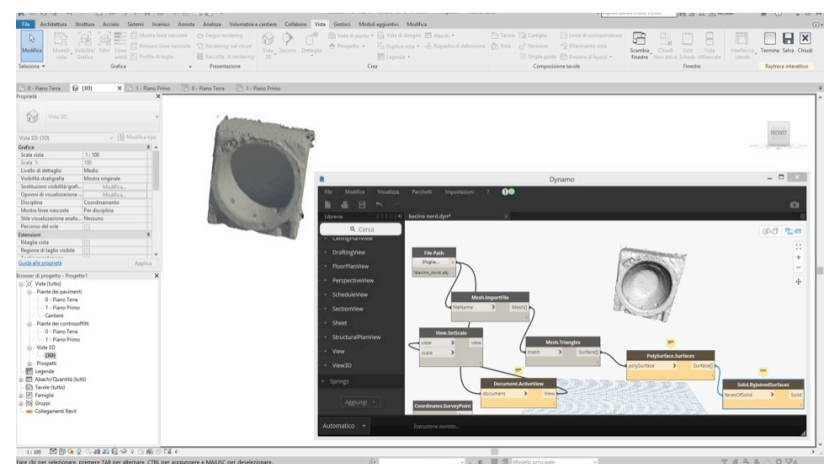

Figure 14: A screenshot into Revit showing the flow chart designed by Dynamo.

\section{CONCLUSIONS}

The Temple of Niuserra has revealed perfect setting for testing an innovative survey methodology and data management, as in this site the archaeological interest can be combined with the not yet clarified structural aspects. On one hand, by using laser scanning and image-based modelling was less time consuming than traditional survey methodologies to obtain an accurate 3D model. On the other hand, the model contains a large amount of information whose management is particularly complex. From this last consideration BIM can be considered a simulation environment working as a cognitive laboratory, where it is possible digitally to compare different hypotheses and architectural choices with the aim to correctly reconstruct the archaeological monument.

BIM is an Information System including various data, organized semantically, can be simple queried and visualized: the digital archive contains identification data, morphological records, typological elements, architectural components describing all the parts of the archaeological context.

Conversely, from the traditional 3D approach, addressed to the virtual reconstruction of a monument, the BIM associates the powerful of 3D modelling techniques with the taxonomy of each single element allowing to generate a transparent and understandable archaeological model.

Currently the more important obstacle to the wider diffusion of BIM in archaeology is the lack of automatic and semi-automatic procedures to transform the point-cloud/mesh in objects and the absence of standardised libraries. Probably, in the future, shared semantic and parametric libraries will allow facing these issues with innovative methods and results. Anyway, the parametric libraries will be the output of a simplification process that will be analysed case by case. BIM in archaeology will require adequate level of reliability, as the digital translation of archaeological data will be carried out on an intrinsic uncertainness greater than the historical buildings.

\section{ACKNOWLEDGEMENTS}

The authors would like to thank Rosanna Pirelli, scientific director of the mission in Abou Gurab. To the research have collaborated also Emanuele Brienza and Giancarlo Iannone.

The project is funded by Italian Foreign Affairs and Cooperation Ministry and University of Naples "L'Orientale". 


\section{REFERENCES}

Achille, C., Lombardini, N. and Tommasi, C., 2015. BIM and cultural heritage: compatibility tests in an archaeological site. In: L. Mahdjoubi, C. A. Brebbia, R. Laing (Eds.), Building Information Modelling (BIM) in Design, Construction and Operations. Southampton, WIT Press, pp. 593-604.

Arnold, D., 1991. Building in Egypt. Pharaonic Stone Masonry. New York -Oxford. Oxford University Press.

Borchardt, L., 1905. Das Re-Heiligtum des Königs Ne-Woser$R e$, I Bd. Der Bau (hrsg. von F.W. von Bissing). Berlin.

D’Andrea, A., Pirelli, R., Iannone, G., Nuzzolo, M. and Zanfagna, P., 2014. The Italian Archaeological Mission in the The Sun Temple of Niuserra at Abu Ghurab, Egypt. The Use of Combined Technologies and New Perspectives of Study on the Monument: the two First Campaigns. In: Newsletter di Archeologia CISA, Volume (5), pp. 58-98. Available at: http:/www.unior.it/userfiles/workarea_231/file/NL5/Testi\%20P DF/DAndrea,Pirellietalii.pdf (last accessed on December 2018).

Fassi, F., Achille, C., Mandelli, A., Rechichi, F. and Parri, S., 2015. A new idea of BIM system for visualization, web sharing and using huge complex 3D models for facility management. In: The International Archives of the Photogrammetry, Remote Sensing and Spatial Information Sciences, 40(5/W4), pp. 359366.

Historic England, 2017. BIM for heritage: developing a Historic Building Information Model. Swindon. Historic England.

London Charter. For the Computer-Based Visualisation of Cultural Heritage. www.londoncharter.org (last accessed on December 2018)

Lopez, F. J., Lerones, P. M., Llamas, J., Gomez-GarcìaBermejo, J. and Zalama, E., 2018. A review of Heritage Building Information Modelling (H-BIM). In: Multimodal Technologies and Interaction 2, 21, pp .1-29. doi:10.3390/mti2020021

Murphy, M., McGovern, E. and Pavia, S., 2007. Parametric vector modelling of laser and image surveys of 17 th century classical architecture in Dublin. In: Arnold D., Chalmers A., Niccolucci F. (Eds.), VAST 2007, Future Technologies to Empower Heritage Professionals, The $8^{\text {th }}$ International Symposium on Virtual Reality, Archaeology and Intelligent Cultural Heritage, Short and Project Papers, 26 $6^{\text {th }}-29^{\text {th }}$ November 2007, Brighton, United Kingdom, pp. 79-84.

Nuzzolo, M. and Pirelli, R., 2011. New archaeological investigation in the sun temple of Niuserra in Abu Ghurab. In: Barta, M., Coppens, F., Krejci, J. (Eds.) Abusir and Saqqara in the Year 2010. Proceedings of the Conference held in Prague, May 31st - June 4th, pp. 664-679.

Scianna, A., Serlorenzi, M., Gristina, S., Filippi, M. and Paliaga, S., 2015. Sperimentazione di tecniche BIM sull'archeologia romana: il caso delle strutture rinvenute all'interno della cripta della chiesa dei SS. Sergio e Bacco in Roma. In: Archeologia e Calcolatori, supp. 7, pp. 199-212.

Sevilla Charter. International Principles of Virtual Archaeology. http://smartheritage.com/seville-principles/seville-principles (last accessed on December 2018)

Tobiáš, P., 2016. BIM, GIS and semantic models of cultural heritage buildings. In: Geoinformatics, FCE CTU 15(2), pp. 2742.
Trizio, I., Savini, F. and Giannangeli, A., 2018. The Building Information Modelling for the documentation of an archaeological site. In: Proceedings of 2018 IEEE International Workshop on Metrology for Archaeology and Cultural Heritage (MetroArchaeo 2018), Cassino, Italy, October 22-24, 2018, pp. 199-205. 